Cahiers $d u$ MONDE RUSSE

\section{Cahiers du monde russe}

Russie - Empire russe - Union soviétique et États indépendants

$43 / 4 \mid 2002$

Intellectuels et intelligentsia

\title{
Patricia Kennedy Grimsted, Trophies of war and empire
}

\section{Francine-Dominique Liechtenhan}

\section{OpenEdition}

\section{Journals}

Édition électronique

URL : https://journals.openedition.org/monderusse/4037

DOI : 10.4000/monderusse.4037

ISSN : $1777-5388$

\section{Éditeur}

Éditions de l'EHESS

\section{Édition imprimée}

Date de publication : 30 décembre 2002

Pagination : 743-744

ISBN : 2-7132-1796-2

ISSN : $1252-6576$

Référence électronique

Francine-Dominique Liechtenhan, «Patricia Kennedy Grimsted, Trophies of war and empire », Cahiers du monde russe [En ligne], 43/4 | 2002, mis en ligne le 11 septembre 2013, consulté le 04 septembre 2022. URL : http://journals.openedition.org/monderusse/4037 ; DOI : https://doi.org/10.4000/ monderusse. 4037

Ce document a été généré automatiquement le 4 septembre 2022.

2011 


\title{
Patricia Kennedy Grimsted, Trophies of war and empire
}

\author{
Francine-Dominique Liechtenhan
}

\section{RÉFÉRENCE}

Patricia KENNEDY GRIMSTED, Trophies of war and empire. The archival heritage of Ukraine, World War II, and the international politics of restitution. Préface de Charles Kecskeméti. Cambridge, MA, Harvard University Press, 2001, 750 p.

1 Patricia Kennedy Grimsted s'est fait connaître par ses importantes publications sur les pratiques archivistiques en Russie et ses guides des archives de la Fédération de Russie. Elle aborde ici le problème des archives ukrainiennes, pillées par les nazis puis par les Soviétiques pendant la Seconde Guerre mondiale, en faisant une large place aux problèmes des restitutions et réparations qui se posent depuis l'effondrement de l'URSS. L'Allemagne et la Fédération de Russie sont parvenues à signer des accords ponctuels, mais le dialogue s'enlise entre Kiev et Moscou, la capitale russe prenant prétexte d'une longue histoire commune pour conserver des archives et œuvres d'art ukrainiennes, argumentation dans laquelle même la législation internationale s'enlise.

2 L'auteur essaie dans un premier chapitre de définir le patrimoine ukrainien en proposant une typologie des documents appartenant à ce pays. Cette démarche délicate aurait nécessité des développements historiques remontant au-delà de la fin de l'empire tsariste où se firent les premiers classements de documents, et tenant compte de l'espace ukrainien modifié, déchiré à la suite des innombrables conflits entre Russie, Pologne et Lituanie. Tentative méritoire, mais qui demeure forcément non exhaustive vu la délocalisation de fonds entiers, qui, pour une grande partie, n'ont jamais regagné leurs dépôts d'origine.

3 La seconde partie des Trophies of war est consacrée aux destructions et pillages qu'a subis l'Ukraine pendant la Seconde Guerre mondiale. Patricia Kennedy Grimsted évoque la bibliographie récente des ouvrages consacrés aux exactions des Allemands, mais passe 
trop brièvement sur les destructions ou les vols commis à Kharkov ou à Kiev où moins de $10 \%$ du patrimoine furent sauvegardés. Selon des chiffres récents, 46 millions de documents d'archives disparurent des archives nationales et régionales ukrainiennes, sans parler des 51 millions de livres et 283782 objets dérobés dans les bibliothèques et musées. Sans nier les crimes des nazis en URSS, l'auteur concentre son attention sur la revanche des Soviétiques, leurs propres ravages, falsifications des statistiques des pertes, attribution de certaines dégradations ou disparitions à l'ennemi alors qu'elles incombaient à l'Armée rouge. Certains officiers soviétiques ont ainsi préféré détruire archives et bibliothèques plutôt que de les livrer à l'envahisseur. Parfois, il s'agissait d'actes dévastateurs gratuits. Ces actes de violence eurent dans tous les cas des suites catastrophiques pour l'historiographie ukrainienne. Un développement plus strictement chronologique des événements aurait évité de laisser l'impression d'un certain déséquilibre dans l'appréciation des crimes de guerre commis.

On trouvera également dans cet ouvrage, dont c'est un des points forts, les lois internationales, les résolutions de l'UNESCO, de l'ONU ou des accords bilatéraux définissant le pillage de documents d'archives en temps de guerre et les conditions de restitution, surtout dans le cas où il y a une succession d'États (l'ex-URSS et pays de la CEI).

5 Le choix thématique, la division de l'ouvrage au détriment de la chronologie n'en facilitent pas la lecture, mais, considéré comme un manuel, celui-ci a le grand mérite de donner un aperçu complet des problèmes qui se posent quant aux pillages de guerre et aux restitutions d'objets de valeurs, de bibliothèques et d'archives, qui évoquent autant un « droit du sol » qu'un « droit des peuples » à disposer de leur patrimoine. 